$\forall \therefore 5 A-C D-20424 \%$

\title{
CONTINUOUS NANOCLIMATE DATA (1985-1988) FROM THE ROSS DESERT (MCMURDO DRY VALLEYS) CRYPTOENDOLITHIC MICROBIAL ECOSYSTEM
}

\author{
CHRISTOPHER P. MCKAY \\ Space Science Division, NASA Ames Research Center, Moffett Field, California 94035 \\ James A. Nienow,' Michael A. Meyer, ${ }^{2}$ and E. Imre Friedmann \\ Department of Biological Science, Florida State University, Tallahassee, Florida 32306
}

\begin{abstract}
We have collected year-round nanoclimate data for the cryptoendolithic microbial habitat in sandstones of the Ross desert, Antarctica, obtained with an Argos satellite data system. Data for two sites in the McMurdo Dry Valleys are available: Linnaeus Terrace, January 1985 to June 1988, and Battleship Promontory, 1986-1987. The focus of this research is ecological, and hence year-round environmental data have been obtained for the ambient environment as well as for conditions within the rock. Using data from the summer, we compare the conditions inside the rock to the outside weather. This demonstrates how the rock provides a shelter for the endolithic microbial community. The most important property of the rock is that it absorbs the summer sunlight, thereby warming up to temperatures above freezing. This warming allows snowmelt to seep into the rock, and the moisture level in the rocks can remain high for weeks against loss to the dry environment.
\end{abstract}

\section{INTRODUCTION}

The Ross desert is a true desert in Antarctica, extending to most of the McMurdo Dry Valleys, the largest ice-free region of the continent. This area is free of ice because it is shielded by the Transantarctic Mountains from the flow of ice from the polar plateau. The entire coastal region near McMurdo Sound, including the polar plateau, receives very little precipitation [ $\mathrm{Schw}$ erdtfeger, 1970]. This, together with the low albedo and relatively warm and dry föhn winds descending from the polar plateau, results in extremely arid conditions in the dry valleys [Riordan, 1975, 1982; Bromley, 1985; Clow et al., 1988].

The valleys and the surrounding mountains form an extremely cold desert environment in which there are no visible signs of life. However, microorganisms live hidden in the perennially ice covered lakes [Parker et al., 1982] and below the surface of rocks [Friedmann and Ocampo, 1976; Friedmann, 1982]. The cryptoendolithic ecosystem poses intriguing questions about the survival of organisms in cold dry conditions and has been the subject of investigation for many years. The predominant cryptoendolithic community is the lichen-

\footnotetext{
${ }^{1}$ Now at Waycross College, Waycross, Georgia 31501.

${ }^{2}$ Now at Desert Research Institute, Reno, Nevada 89506.
}

dominated community [Friedmann et al., 1988] composed of lichens accompanied by nonlichenized algae, fungi, and bacteria. This community exists in the pore spaces of Beacon sandstone orthoquartzite at a depth of a few millimeters but does not actively bore into the rock. Microbial activity results in the exfoliative weathering of the rock surface [Friedmann, 1982]. Field studies conducted during the austral summers have demonstrated that the nanoclimate conditions in the endolithic zone are very different than those which characterize the macroclimate [Friedmann, 1977; Friedmann et al., 1980; Kappen et al., 1981; McKay and Friedmann, 1985]. These studies have established a need for detailed year-round observations in order to fully understand the differences between the environment within the rock and the outside conditions.

Such a complete set of biological microclimate data is also necessary for a full understanding of the ecosystem and for the construction of numerical models [e.g., Nienow et al., 1988a, $b$ ] to predict the system response to perturbations. Unfortunately, ecological research in Antarctica is hampered by the difficulty in obtaining continuous biometeorological data over the entire year. Often, data have only been obtained for time periods when human observers were present in the field, i.e., during periods of relatively clement weather in the summer season. Even if environmental and logistical 
difficulties could be surmounted, polar ecosystems are often too fragile to withstand a year-round human presence. Hence automatic data acquisition equipment clearly has a role to play in obtaining the requisite data.

Over the last 10 years there has been an ongoing effort to obtain meteorological data from automatic weather stations in the Antarctic [Renard and Salinas, 1977; Stearns and Savage, 1981; Stearns, 1982; Savage et al., 1985; Stearns and Wendler, 1988]. These stations obtain data using standard meteorological instrumentation once every $\sim 200 \mathrm{~s}$. The data are broadcast by radio, and when one of the National Oceanic and Atmospheric Administration (NOAA) series of polar-orbiting satellites is passing overhead, the data are collected and then relayed to ground stations. The fact that the satellites are in polar orbit makes this system particularly well suited for use in polar regions where data transmission to geostationary satellites is often impossible. The total number of satellite passes over a given location averages about seven per day at the equator and up to 28 per day at the poles. For the data reported in this paper, all readings collected during a single satellite pass are averaged together.

We have successfully adapted this system to monitor biologically important environmental parameters, both within the rock habitat and for ambient conditions, on a year-round basis. The initial summaries of the yearround data results for this system were presented by McKay and Friedmann [1984] and more extensively by Friedmann et al. [1987]. These studies were based at Linnaeus Terrace, a location of extensively colonized sandstone rocks in the Wright Valley. In this paper we report the availability of the complete set of data acquired at Linnaeus Terrace from 1984 to 1988 (the data set for Linnaeus Terrace from 1984 to 1986 are published in full detail by Friedmann et al. [1987]) and from a second site, Battleship Promontory, for the years 1986 and 1987. The data set is extensive, and we do not reproduce it here but focus instead on illustrative subsamples of the data, particularly from the summer months. The full data set for both sites is available from the first author.

A detailed quantitative analysis of the yearly hours of the various temperature-light-water combinations based on the computer analysis of the data set, as well as further biological considerations, is published elsewhere [Friedmann et al., 1993].

\section{METHODS AND INSTRUMENTATION}

The system is composed of three components: the sensors, the data-handling and transmitting unit, and the power supply. In this paper we report data obtained from sensors which monitor the air temperature, the temperature of the rock surface in several orientations, the electrical conductivity of the rock (an indication of rock moisture), the wind speed near the ground, the photosynthetically active radiation flux, and the presence of snow. Air temperature is measured at a distance of about $1 \mathrm{~m}$ from the rock sensors and at a height of about $70 \mathrm{~cm}$ above the rock surface. The sensor is screened from direct solar radiation by a polished metal cylinder. A complete description of the methods and instrumentation has been given by Friedmann et al. [1987] and is only briefly reviewed here.

The temperature is sensed with a National Semiconductor (Santa Clara, California) LM134 semiconductor sensor which generates a current that is directly proportional to the absolute temperature. A secondary temperature sensor was composed of a Yellow Springs Instrument (Yellow Springs, Ohio) thermistor device. It is composed of a ceramic bead whose electrical resistance is a sensitive function of temperature. Light measurements of the photosynthetically active radiation (PAR) are obtained using a LiCor (Lincoln, Nebraska) quantum sensor. On Linnaeus Terrace the skylight was measured by shielding a light sensor with a tube such that the view of the sky was limited to a $-50^{\circ}$ region centered on the zenith. In the dry valleys, where the maximum solar elevation is $36^{\circ}$, this ensures that only skylight reaches the sensor, and hence the ratio of this sensor's output to the output from the total light sensor is an indication of cloud cover. Wind is measured with a standard meteorological cup anemometer.

We have developed a method to determine the presence of liquid water in the rock on the basis of electrical conductivity [Friedmann et al., 1987]. The sensor consists of a pair of electrodes separated by about $1 \mathrm{~cm}$. To attach the electrodes to the rock surface, they are soldered into small holes (about $1 \mathrm{~cm}$ deep) drilled into the rocks. The effective conductance between these electrodes is dependent on the mobility of ions that can act as charge carriers. The conductivity depends on all possible current paths on the surface and within the rock to a distance approximately equal to the separation of the two electrodes. When liquid water is present in the rock, salts in solution provide the ions that allow current to flow. If the presence of liquid water is the limiting factor in determining conductivity (i.e., salts are present and the environment is dry), then the conductivity will increase uniformly (but not necessarily linearly) with increasing liquid water. Typical conductivities for the colonized Antarctica rocks saturated with moisture are $1 \mu$ mhos. However, the value of the conductivity that is obtained depends on the total salt content, the porosity of the rock, and the structure of the interstitial channels within the rock. These factors can vary from site to site even within the same rock. For this reason we have not tried to quantify the output of the rock conductivity sensor and use it only as an indicator of the duration of liquid water conditions within the rock. At below freezing temperatures, current can still flow because films of liquid water will still exist. In the rock, water can remain unfrozen in an 
undercooled state at least several degrees below the equilibrium freezing temperature [Meyer et al., 1988]. If the rock is below freezing and ice (which does not conduct) forms within the rock, then the conductivity will decrease. However, sufficient amounts of water may remain to form a conductive channel. As the temperature drops, ice will separate out and the solution concentration will increase [see Franks, 1985] in the remaining conductive channels. The volume of the unfrozen liquid is proportional to the initial solute concentration and the freezing point depression of the solution.

To perform, the measurement a $2-\mathrm{M} \Omega$ resistor is placed in series with the electrodes and a voltage $(5 \mathrm{~V})$ placed across both the fixed resistor and the rock. The voltage drop across the electrodes in the rock (buffered by a unity gain amplifier) indicates the effective conductivity of the rock. The scale of the conductivity reading runs from zero to 255 counts. To prevent polarization of the surface, ac excitation is preferred. However, the low current draw and the low duty cycle allow us to use dc excitation.

We have constructed a device to signal the onset of snowmelt in a qualitative manner [Friedmann and McKay, 1985]. The sensitive element is a $\mathrm{NaCl}$ impregnated fiberglass filter paper disk of approximately $5 \mathrm{~cm}$ diameter. The disks were soaked in $1 \mathrm{M} \mathrm{NaCl}$ and then allowed to dry. In the dry state the dc conductance of the disks is virtually zero. When snow is present at temperatures above the eutectic point of $\mathrm{NaCl}\left(-22^{\circ} \mathrm{C}\right)$, the conductivity of the disk increases dramatically. The input lead to the sensor is a $5-\mathrm{V}$ reference line that pulses only during sampling intervals. The output from the sensor goes directly to the input of the data-handling and transmitting unit. When there is no moisture on the filter paper disk, the input channel records no voltage but becomes a full $5 \mathrm{~V}$ when moisture is present. Thus the snow sensor functions as a binary state switch, providing a uniform signal when any snow is present at temperatures above the eutectic point of $\mathrm{NaCl}$. There is very little current draw even in the presence of moisture, since the input impedance of the data-handling system is very high. Despite the use of a dc excitation, polarization of the sensor is not a problem as a result of the low duty cycle times ( 1 in 200), low current draw, and low moisture levels.

The data are processed by an Argos Data Acquisition Platform (ADAP, manufactured by Polar Research Laboratories, Santa Barbara, California). The ADAP is a self-contained portable data system designed for remote areas. Each unit is capable of sampling 32 channels in the form of analog ground-referenced voltages form zero to $5 \mathrm{~V}$. Preconditioning of the input signals is handled by custom-manufactured electronics (National Research and Technology, Tallahassee, Florida). In operation, the ADAP completes a sampling sequence once every $200 \mathrm{~s}$. In a sampling sequence the unit samples all 32 channels in $1 \mathrm{~s}$, stores the data, digitizes, and then transmits them to the TIROS/NOAA series of satellites. When a satellite's orbit places it within the view of a platform, the transmissions are received and relayed to a ground station.

The major problem in the design of a monitoring station in Antarctica is to ensure survival throughout the dark cold austral winter. Power is supplied by eight 12-V 40 A h lead-acid gel batteries (Power Sonic, Redwood City, California) recharged during the summer months by an array of solar cells. The average power requirement of the system, including ADAP, ancillary electronics, and sensors, is about $0.6 \mathrm{~W}$. This load can be sustained for over 8 months with the battery supply. All electronic components are rated or tested to $-40^{\circ} \mathrm{C}$.

\section{STUDY SITES}

The first study site is located on Linnaeus Terrace $\left(77^{\circ} 36^{\prime} \mathrm{S}, 161^{\circ} 05^{\prime} \mathrm{E}, 1600-1650 \mathrm{~m}\right.$ altitude) in the Asgard Range, on the northern slope of Mount Oliver facing Wright Valley [Friedmann, 1982]. This is also the site of earlier environmental measurements [Kappen et al., 1981; Friedmann et al., 1987]. For a map of the dry valley region see McKay and Friedmann [1985]. Apart from of few dolorite dykes, Linnaeus Terrace consists of Beacon sandstone and is particularly rich in lichendominated cryptoendolithic microbial colonization.

The second site is Battleship Promontory $\left(76^{\circ} 55^{\prime} \mathrm{S}\right.$, $160^{\circ} 55^{\prime} \mathrm{E}, 1600-1650 \mathrm{~m}$ altitude) in the Convoy Range. The name of this large sandstone outcrop facing Alatna Valley aptly expresses its spectacularly ragged morphology. Its geology has been described by Mirsky et al. [1965]. The sandstone rocks of Battleship Promontory are colonized by the lichen-dominated cryptoendolithic community. Sandstones adjacent to the dolorite talus slope of Mount Gran are wetted by snowmelt water carried by the dolerite rubble which acts as an aquifer, and here the sandstone is colonized by the GloeocapsaHormathonema (cyanobacteria) community which requires more liquid water than lichens [Friedmann et al., 1988].

\section{RESULTS}

Daily average temperatures and sunlight on Linnaeus Terrace station are shown in Figure 1. The light is the photon flux (in units of $6.02 \times 10^{20}$ photons $\mathrm{m}^{-2} \mathrm{~s}^{-1}$ ) in the 400 - to $700-\mathrm{nm}$ spectral region. The dicotomy between summer and winter is clearly shown. Also shown in Figure 1 is the temperature on the horizontal surface of a colonized rock. The top surface of this particular rock has been previously monitored [McKay and Friedmann, 1985; Friedmann et al., 1987].

Figure 2 shows the data in more detail for the month of January 1987. Here we also show the results of the sky sensor. When the ratio of the total light to the sky 


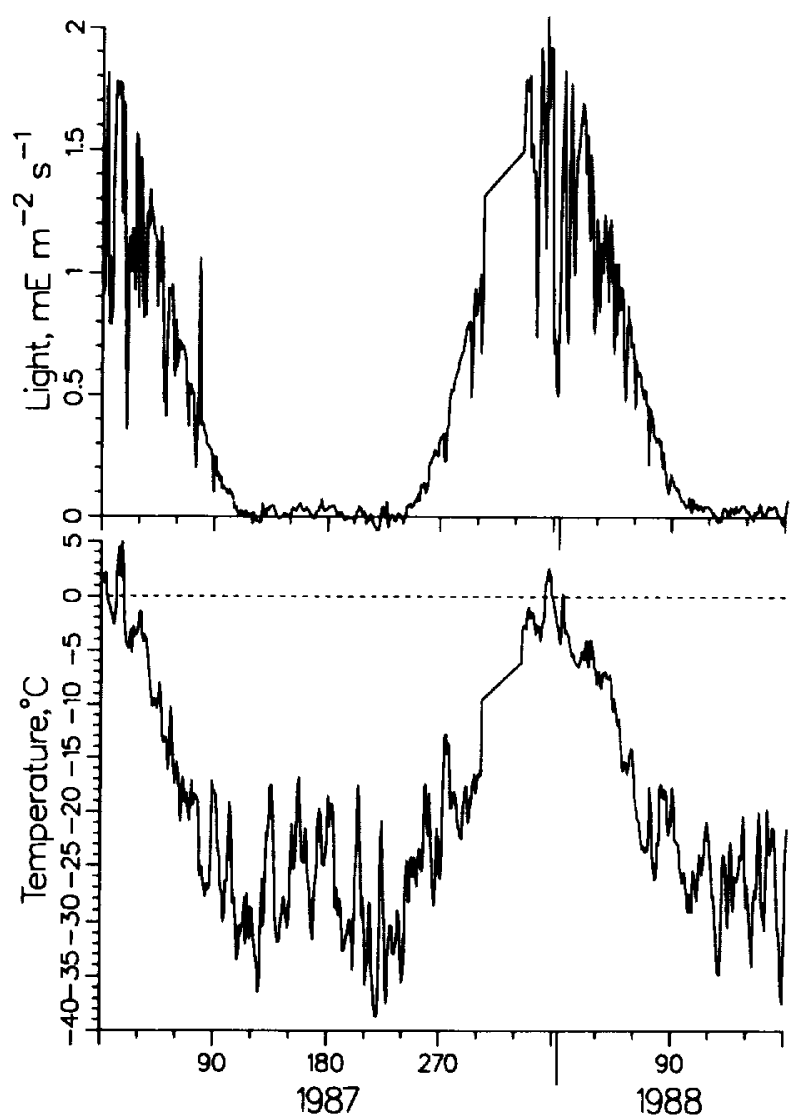

Fig. 1. Daily average light and temperature during 1987 and 1988 on Linnaeus Terrace. Photosynthetically active radiation $(400-700 \mathrm{~nm})$ is shown in the top panel $\left(E=6.02 \times 10^{23}\right.$ photons). Temperature of a horizontal rock surface is shown in the bottom panel.

light approaches values close to -3 , this is an indication that the sky is completely cloudy. When this occurs, the temperatures drop. The rock and air temperatures are both shown in the bottom panel of Figure 2. As expected [Kappen et al., 1981; McKay and Friedmann, 1985; Friedmann et al., 1987], the rock temperature is warmer than the air temperature. The data shown here are daily averages, and the rock is uniformly about $5^{\circ} \mathrm{C}$ warmer than the air. The difference varies throughout the day from about $10^{\circ}-15^{\circ} \mathrm{C}$ at midday to nearly zero at midnight [e.g., McKay and Friedmann, 1985].

Figures 3 and 4 show selected climate results for Battleship Promontory. Daily average air temperatures at Battleship Promontory for 1986 and 1987 are shown in the bottom panel of Figure 3. The top panel of that figure shows the temperature difference between an eastern facing rock surface and air. The rock is significantly warmer during the summer months as a result of solar heating. During winter the rock surface is slightly colder than the air. This is the expected result since the rock surface will cool efficiently by infrared emission.

Figure 4 shows the daily average snow and rock moisture for Battleship Promontory for 1986 and 1987. The presence of snow is detected by $\mathrm{NaCl}$ disks, and the rock moisture determined by changes in conductivity. The results are qualitative only and have been normalized. The results suggest that the Battleship Promontory site receives snow with a frequency not unlike that reported for Linnaeus Terrace by Friedmann et al. [1987]. Both sites, which are located over $1600 \mathrm{~m}$ above the valley floors, receive much more regular snowfalls than the valley floors below [Riordan, 1975; Thompson et al., 1971; Clow et al., 1988].

As seen in Figures 1 and 3, after January the flux of sunlight is reduced, temperatures drop, and the growing season for the endolithic communities is essentially over. Rock temperature on Linnaeus Terrace did not rise above freezing after mid-February. Throughout the winter months the temperatures remain quite low.

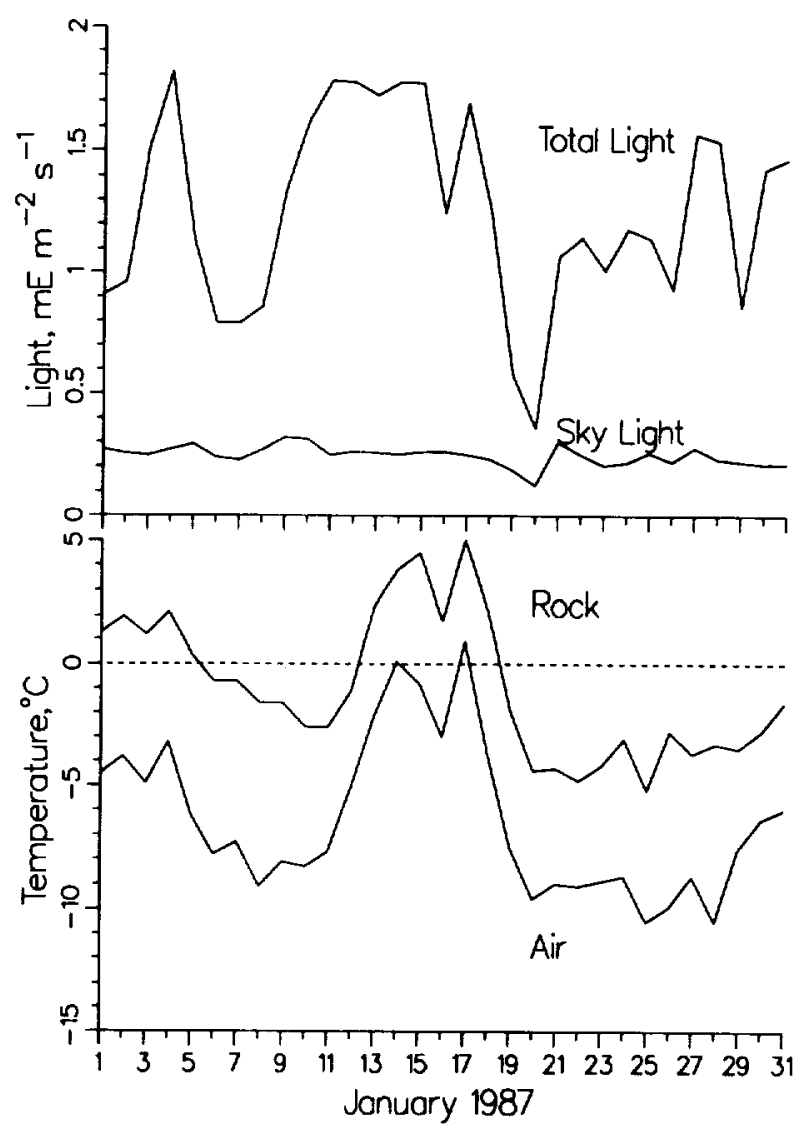

Fig. 2. Daily average light and temperature during January 1987 on Linnaeus Terrace. Light and rock temperature are the same as in Figure 1. Also shown is the sky light (light only from a cone of about $50^{\circ}$ centered on the zenith) and the air temperature. Under completely cloudy conditions, total light is about 3 times the sky light. 
There is a variation of about $20^{\circ} \mathrm{C}$, which can be seen, for example, in the data for winter 1986, 1987, and 1988. The rise in temperature during winter, often by $20^{\circ} \mathrm{C}$, is due to föhn winds [Schwerdtfeger, 1970; Riordan, 1975, 1982; Bromley, 1985; Clow et al., 1988]. In September the sunlight becomes measurable again, and the air temperatures begin to rise. Rock surface temperature begins to rise above freezing in November and maximizes in late December and early January. This general pattern repeats from year to year.

\section{DISCUSSION}

The year-round data mirror seasonal patterns not only in the Ross desert nanoclimate but also in the mesoclimate of the McMurdo Dry Valleys in general. Summer extends from mid-November to late February and is the period during which virtually all metabolic activity occurs. The phasing of the seasons (the difference

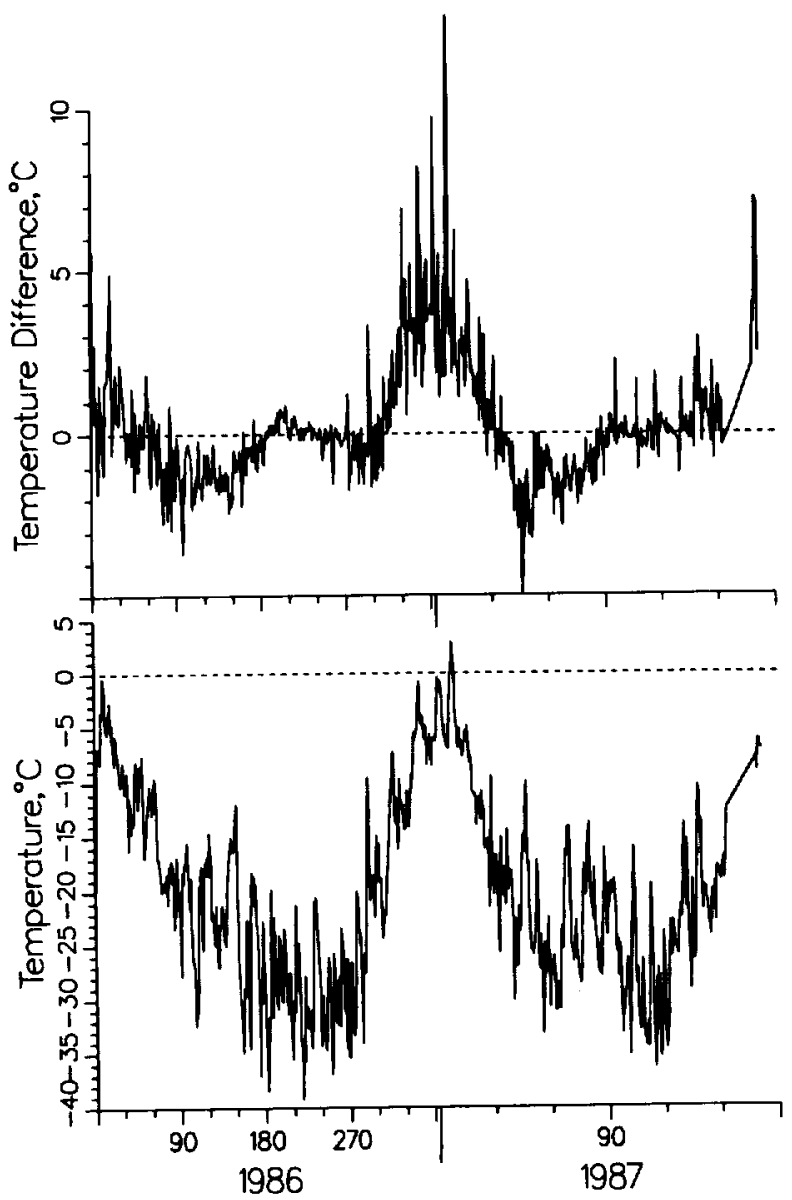

Fig. 3. Daily average air temperatures at Battleship Promontory for 1986 and 1987 are shown in the bottom panel. The top panel shows the temperature difference between rock and air. The rock is significantly warmer during the summer months and slightly cooler in the winter.

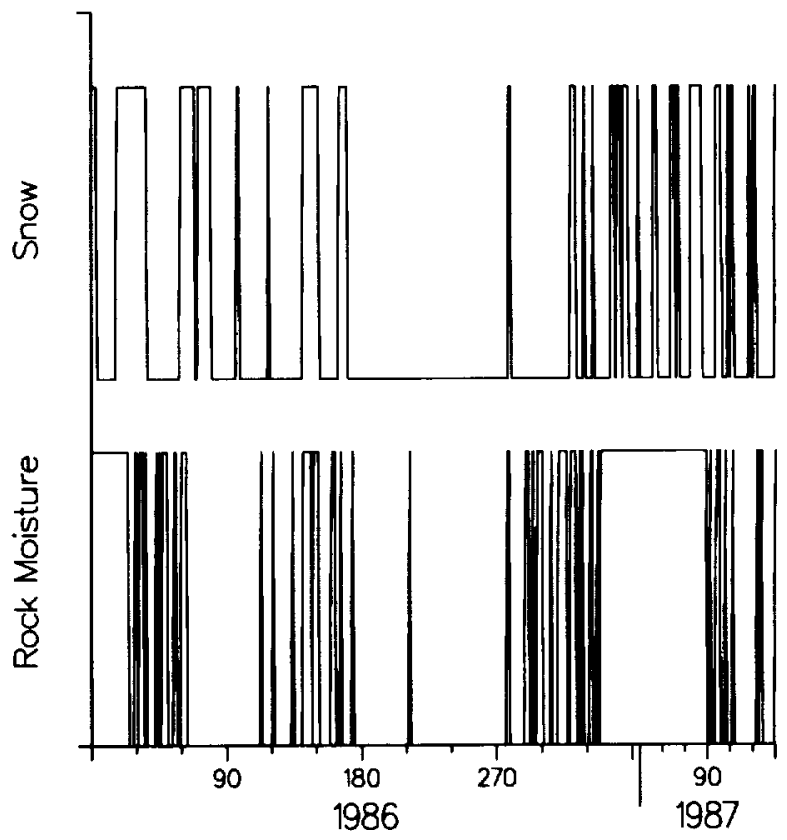

Fig. 4. Daily average snow and rock moisture for Battleship Promontory for 1986 and 1987. The presence of snow is detected by $\mathrm{NaCl}$ disks, and the rock moisture determined by changes in conductivity. The results are qualitative only and have been normalized.

between the summer solstice and the warmest day of the year) is dominated by the solar radiation, and hence summer in Antarctica is more symmetrical with respect to the solstice (December 21) than the summer season in the temperate regions of the southern hemisphere. During the austral summer the sun shines continuously, often raising the rock temperatures above the freezing point. The summer is also the period of the most snowfall. This, and the warm rock surfaces, ensure a supply of water within the rocks [Friedmann, 1978]. Once water has seeped into the rock, it is retained long after the ambient conditions return to a dry state. Fall, from late February to mid-April, marks the transition to continuous night and rock temperatures consistently below freezing. Snowfalls continue, but the rock temperatures are too low to result in melting. Winter, from mid-April to August, is the period of continuous darkness, and temperatures are determined by the balance between radiative cooling and heating due to sporadic föhn winds [e.g., Clow et al., 1988]. Spring extends from September to mid-November and represents the transition from continuous night to continuous day. Rock temperatures remain below freezing, and there is no significant melting of snow or metabolic activity.

It is interesting to consider how the pattern of climate varies from year to year because of interannual variability in climate. There are two key processes that control nanoclimate of the endolithic habitat: sunlight warming 
TABLE 1. Comparison of the Ambient Conditions and the Advantages of the Cryptoendolithic Environment

\begin{tabular}{lll}
\hline Factor & \multicolumn{1}{c}{ Ambient Condition } & \multicolumn{1}{c}{$\begin{array}{c}\text { Advantages of the Cryptoendolithic } \\
\text { Environment }\end{array}$} \\
\hline Temperature & Low air temperature. & $\begin{array}{c}\text { Direct solar heating warms the rocks and } \\
\text { thermal inertia of the rocks dampens } \\
\text { variations. } \\
\text { Rock pore spaces hold moisture for weeks } \\
\text { after a snowmelt. }\end{array}$ \\
$\begin{array}{l}\text { Wind } \\
\text { Radiation }\end{array}$ & $\begin{array}{l}\text { Little snow; air humidity averages } \\
\text { Abrasion by strong föhn winds. } \\
\text { Solar ultraviolet flux and intense } \\
\text { visible radiation. }\end{array}$ & $\begin{array}{l}\text { Protection is given by the rock. } \\
\text { The rock significantly attenuates all } \\
\text { radiation, particularly UV, but limits } \\
\text { depths of colonization. }\end{array}$ \\
\hline
\end{tabular}

the rock and snowmelt providing a source of liquid water. The first of these is not likely to vary to a great extent from year to year since the solar radiation is controlled by the solar zenith angle. The second factor, however, does show considerable interannual variation. Some years there are numerous and heavy snowfalls, while other years there are only light and occasional snows. This variation could be tied to larger weather patterns which transport moist air from other regions. Assessing the nature of any interannual variability would require a longer systematic monitoring than we have accomplished.

The climate of the McMurdo Dry Valleys is cold and dry, and on the surface there are virtually no signs of life, especially in the typical desert areas (Ross desert). More humid microsites with mosses, lichens, and cyanobacterial mats occur only when meltwater from glaciers or from snow is available. Yet, within the sandstone of the Ross desert, colonized by cryptoendolithic microorganisms, conditions are suitable for life. On the basis of year-round data we can characterize the ambient environment and assess what advantages the endolithic habitat provides. The environmental factors that make life on the surface of soils or rocks impossible are listed in Table 1. Although we have listed them in a priority order, all of these factors are operating. On the basis of our studies of the cryptoendolithic habitat we can suggest how the rock substrate provides protection to organisms.

Among adverse biological factors the most significant is air temperature, which is generally below freezing, with only brief excursions to temperatures above $0^{\circ} \mathrm{C}$. The mean annual air temperature is below $-20^{\circ} \mathrm{C}$, and even during the warmest month of the year, January, the monthly mean air temperature is several degrees below freezing (see also Friedmann et al. [1987]). By contrast, temperatures within the rocks can be relatively warm with tens to hundreds of hours spent above $0^{\circ} \mathrm{C}$. In addition, direct solar heating of the rock can raise temperatures to up to $17.8^{\circ} \mathrm{C}$ and provides a thermally stable environment [McKay and Friedmann, 1985].
Water is an essential requirement for life, and the ambient conditions in the valleys are extremely dry compared to the levels necessary to support life. There is little precipitation, and much of it is blown away or sublimes and therefore is unavailable for organisms [Friedmann, 1978]. Again, the endolithic habitat provides an advantage. Snow on the surface of the rocks is melted by the absorption of radiation, warming the rock to temperatures above the freezing point. Water then seeps quickly into the porous rock [Friedmann, 1978]. Although the ambient environment rapidly dries, water is retained within the rock matrix and only gradually decreases. Typically, new snow recharges the rock water content before the levels have dropped appreciably. The data show (e.g., Figure 4) that after a summer snowmelt the moisture level in the rocks can remain high for weeks while the air relative humidity remains quite low (see al so Kappen et al. [1981] and Friedmann et al. [1987]).

In addition to providing a favorable thermal and moisture regime, the rock habitat functions as a mechanical shield against wind abrasion and extreme ultraviolet or visible light [Nienow et al., 1988b]. Thus the cryptoendolithic habitat, because of the dramatic difference between its nanoclimate and the outside conditions, constitutes a refuge for life in an otherwise abiotic and "hostile" environment.

Acknowledgments. We thank the members of the field parties and the helicopter crews for assistance in deployment of the equipment. This work was supported by NASA grants NSG 7337 and NAGW 1971 and by NSF grants DPP80-17581 and DPP83-14180 to E.I.F.

\section{REFERENCES}

Bromley, A. M., Weather observations, Wright Valley, Antarctica, report, 37 pp., N. Z. Meteorol. Serv., Wellington, 1985.

Clow, G. D., C. P. McKay, G. M. Simmons, Jr., and R. A. Wharton, Jr., Climatological observations and predicted sublimation rates at Lake Hoare, Antarctica, J. Clim., I, 715-728, 1988. 
Franks, F., Biophysics and Biochemistry at Low Temperatures, Cambridge University Press, New York, 1985.

Friedmann, E. I., Microorganisms in Antarctic desert rocks from dry valleys and Dufek Massif, Antarct. J. U.S., 12, 26-30, 1977.

Friedmann, E. I., Melting snow in the dry valleys is a source of water for endolithic microorganisms, Antarcr. J. U.S., 13, $162-163,1978$.

Friedmann, E. I., Endolithic microorganisms in the Antarctic cold desert, Science, 215, 1045-1053, 1982.

Friedmann, E. I., and C. P. McKay, A method for the continuous monitoring of snow: Application to the cryptoendolithic microbial community of the Ross desert, Antarctica, Antarct. J. U. S., 20, 179-181, 1985.

Friedmann, E. I., and R. Ocampo, Endolithic bluegreen algae in the dry valleys: Primary producers in the Antarctic desert ecosystem, Science, 193, 1247-1249, 1976

Friedmann, E. I., Y. Garty, and L. Kappan, Fertile stages of endolithic lichens in the dry valleys of southern Victoria Land, Antarct. J. U. S., 15, 166-167, 1980.

Friedmann. E. I., C. P. McKay, and J. A. Nienow, The cryptoendolithic microbial environment in the Ross desert of Antarctica: Continuous nanoclimate data, 1984 to 1986 , Polar Biol. 7, 273-287, 1987.

Friedmann, E. I., M. Hua, and R. Ocampo-Friedmann, Cryptoendolithic lichens and cyanobacterial communities of the Ross desert. Antarctica, Polarforschung, 58, 251-259, 1988.

Friedmann, E. I., L. Kappen, M. A. Meyer, and J. A. Nienow, Long-term productivity in the cryptoendolithic microbial community of the Ross desert, Antarctica, Microbiol. Ecol., $25,51-69,1993$.

Kappen, L., E. I. Friedmann, and Y. Garty, Ecophysiology of lichens in the dry valleys of southern Victoria Land, Antarctica, 1, Microclimate of the cryptoendolithic lichen habitat. Flora Jena, 17I, 216-235, 1981.

McKay, C. P., and E. I. Friedmann, Continuous temperature measurements in the cryptoendolithic microbial habitat by satellite-relay data acquisition system, Antarct. J. U.S., 19 , 170-172, 1984.

McKay, C. P., and E. I. Friedmann, The cryptoendolithic microbial environment in the Antarctic cold desert: Temperature variations in nature, Polar Biol., 4, 19-25, 1985.

Meyer, M. A., G. H. Huang, G. J. Morris, and E. I. Friedmann, The effect of low temperatures on Antarctic endolithic green algae, Polarforschung, 58, 113-119, 1988.

Mirsky, A., S. B. Treves, and P. E. Calkin, Stratigraphy and petrography, Mount Gran area, southern Victoria Land,
Antarctica, in Geology and Paleontology of the Antarctic, Antarct. Res. Ser., vol. 6, edited by J. B. Hadley, pp. 145-175, AGU, Washington, D. C., 1965.

Nienow, J. A., C. P. McKay, and E. I. Friedmann. The cryptoendolithic microbial environment in the Ross desert of Antarctica: Mathematical models of the thermal regime, Microbial Ecol., I6, 253-270, 1988a.

Nienow, J. A., C. P. McKay, and E. I. Friedmann. The cryptoendolithic microbial environment in the Ross desert of Antarctica: Light in photosynthetically active region, Microbial Ecol., 16, 271-289, $1988 b$.

Parker, B. C., G. M. Simmons, Jr., K. G. Seaburg, D. D. Cathey, and F. T. C. Allnutt, Comparative ecology of plankton communities in seven Antarctic oasis lakes, $J$. Plankton Res., 4, 271-286, 1982.

Renard, R. J., and M. G. Salinas. The history, operation, and performance of an experimental automatic weather station in Antarctica, Rep. NPS-63RD7710. 57 pp., Nav. Postgrad. Sch., Monterey, Calif., 1977.

Riordan, A. J., The climate of Vanda Station, Antarctica, in Climate of the Arctic, edited by G. Weller and S. A. Bowling, pp. 268-275, Geophysical Institute, University of Alaska, Fairbanks, 1975.

Riordan, A. J., Formulation and testing of a climatonomic simulation of the microclimate of the dry valleys and of the Little America V Station in Antarctica, Bounday Layer Meteorol., 24, 295-329, 1982.

Savage, M. L., C. R. Stearns, and D. Flemming, Antarctic automatic weather station data for the calendar year 1980 , report, 72 pp., Dep. of Meteorol., Univ, of Wis., Madison, 1985.

Schwerdtfeger, W., The climate of the Antarctic, in World Survey of Climatology, vol. 14. The Climate of the Antarctic, edited by S. Orvig, pp. 253-355, Elsevier, New York, 1970.

Stearns, C. R., Antarctic automatic weather stations, 19811982, Antarct. J. U. S., 17, 217-219, 1982.

Stearns, C. R., and M. L. Savage, Automatic weather stations, 1980-1981, Antarct. J. U. S., 16, 190-192, 1981.

Stearns, C. R., and G. Wendler, Research results from Antarctic automatic weather stations, Rev. Geophys., 26, 45-61. 1988.

Thompson, D. C., R. M. F. Craig, and A. M. Bromley, Climate and surface heat balance in an Antarctic dry valley, $N . Z . J$. Sci., 14, 245-251, 1971.

(Received March 18, 1991 . accepted April 7, 1993.) 
